\title{
Charge nurse facilitated clinical debriefing in the emergency department
}

\author{
Stuart Rose, MB BCh*; Adam Cheng, MD*†
}

\section{ABSTRACT}

This paper describes the development and implementation of the INFO (immediate, not for personal assessment, fast facilitated feedback, and opportunity to ask questions) clinical debriefing process. INFO enabled charge nurses to facilitate a group debriefing after critical events across three adult emergency departments (EDs) in Calgary, Alberta. Prior to implementation at our institutions, ED critical event debriefing was a highly variable event. Post-implementation, INFO critical event debriefings have become part of our ED culture, take place regularly in our EDs (254 documented debriefings between March 2016 and September 2017), with recommendations arising from these debriefings being introduced into clinical practice. The INFO clinical debriefing process addresses two significant barriers to regular ED clinical debriefing: a lack of trained facilitators and the focus on physician-led debriefings. Our experience shows that a nurse-facilitated debriefing is feasible, can be successfully implemented in diverse EDs, and can be performed by relatively inexperienced debriefers. A structured approach means that debriefings are more likely to take place and become a routine part of improving team management of high stakes or unexpected clinical events.

\section{RÉSUMÉ}

Il sera question, dans le présent article, de l'élaboration et de la mise en œuvre du processus de réunion-bilan clinique, appelée INFO (d'après l'anglais Immediate, Not for personal assessment, Fast facilitated feedback and Opportunity to ask questions). La formule INFO permet à des infirmières responsables d'animer des réunions de bilan clinique après des événements très graves, dans trois services des urgences (SU) pour adultes, à Calgary (Alberta, Canada). Avant la mise en œuvre du processus dans les établissements en question, la tenue de réunions-bilan consécutives à des événements gravissimes au SU était très variable; depuis la mise en œuvre de la démarche, ces réunions font partie intégrante de la culture du personnel de soins et ont lieu fréquemment dans les trois SU participants (254 réunions-bilan documentées entre mars 2016 et septembre 2017). De plus, les recommandations formulées au cours de ces réunions trouvent maintenant écho en pratique clinique. Le processus des séances INFO vise à surmonter deux obstacles importants à la tenue habituelle de réunions-bilan clinique au $\mathrm{SU}$, soit le manque d'animateurs formés et le point de mire sur les réunions animées par les médecins. L'expérience montre qu'il est possible de tenir des réunionsbilan animées par des infirmières, d'implanter ce type de réunion dans divers SU et de confier la conduite de ces réunions à des animateurs ayant relativement peu d'expérience. Le processus structuré d'INFO rend plus probable la tenue de réunions-bilan et fait de celles-ci un composant de l'amélioration de la gestion collective d'événements à grands enjeux ou d'événements cliniques imprévus.

\begin{abstract}
Keywords: clinical debriefing, post resuscitation debriefing, nurse facilitated debriefing, inter-professional, real event debriefing
\end{abstract}

\section{BACKGROUND}

Post-event debriefing, recommended by the American Heart Association (AHA), ${ }^{1}$ provides an opportunity for the team to reflect and learn from their performance. We define post-event debriefing as facilitated interprofessional team reflection after a clinical event that focuses on improving both system and team performance. Despite guidelines on how to implement a clinical debriefing program ${ }^{2,3}$ and evidence that debriefing is associated with improved patient care, ${ }^{4}$ published literature suggests that debriefing is rare after critical emergency department (ED) events and resuscitations. ${ }^{5}$

Time constraints, unrelenting care demands, and lack of available, appropriately trained facilitators are barriers to a consistent clinical debriefing. ${ }^{6}$ Data suggest that physicians facilitate $70 \%$ to $90 \%$ of real-event debriefings,${ }^{5-8}$ but ED care demands impact physician availability. Although able to participate in a short debriefing as a team member, the physician's ability to regularly facilitate debriefings may be impacted by the extra time needed to coordinate a debriefing. This compromises the feasibility and sustainability of physician-led debriefing programs. To address this issue, we explored the use of charge nurses as the designated group responsible for facilitating clinical debriefings.

\section{PURPOSE}

The purpose of this project was to develop a feasible and sustainable charge-nurse-facilitated clinical debriefing program across Calgary area adult EDs.

From the *Department of Emergency Medicine and tDepartment of Pediatrics, University of Calgary, Calgary, AB.

Correspondence to: Stuart Rose, 58 Discovery Ridge View, SW, Calgary, AB T3H 4P9; Email: scrose02@gmail.com

(C) Canadian Association of Emergency Physicians

CJEM 2018;20(5):781-785

DOI 10.1017/cem.2018.369 
Before the INFO process was implemented, no specific group was responsible for facilitating debriefings in Calgary EDs. When debriefings did occur, they were facilitated by the physician team leader; however, time pressures and the invariable backlog of waiting patients limited physician ability to facilitate debriefings.

We recognized that ED charge nurses have clinical knowledge, operational awareness, and an understanding of team roles and expertise within their departments. They usually observe resuscitations but are not allocated a specific role, so are more situationally aware and ideally suited to facilitate post-event debriefings. When resuscitations end, ED nurses and physicians normally return immediately to other patient care responsibilities and become immersed in clinical work, but charge nurses do not have specific patient assignments, allowing them to prioritize the clinical debriefing process.

The Calgary ED charge nurse group expressed a willingness to take on responsibility for clinical debriefing in the ED, and agreed that facilitating INFO sessions was within their scope of practice. Designating this to our charge nurses allowed us to focus training on a small, specific group who then assumed an ongoing oversight of the debriefing process.

\section{DESCRIPTION OF THE INNOVATION}

Based on successful principles in healthcare and other industries, ${ }^{9}$ we developed a clinical debriefing intervention called INFO (immediate, not for personal assessment, fast facilitated feedback, and opportunity to ask questions). INFO implementation was a stepwise process. Firstly, a debriefing tool was developed to specifically support the novice debriefer (Figure 1). AHA guidelines provide examples of several debriefing tools. ${ }^{10}$ These tools and, in particular, the DISCERN tool, were referenced in developing a draft version of the tool. $^{8,10}$ Modifications included the provision of a structured suggested format, the use of a pre-briefing script, and setting the climate for the debriefing by establishing psychological safety. Scripted statements were used to make the debriefing tool more supportive for the novice and encourage a safe environment for debriefing.

The second step was achieving inter-professional engagement and support, which involved a front-end needs assessment, engagement of key stakeholder groups (especially physicians and nurses), encouragement of their involvement in tool development, incorporation of their feedback as appropriate, and the identification of physician and nursing champions.

The third step was a 4-hour "Teach the Teacher" (T3) workshop aimed at the nursing champion and nurse educators. T3 graduates assumed the role of faculty for teaching the INFO Basics workshop, which allowed us to train our charge nurse groups and build facilitator training capacity.

In the fourth step, the 2-hour INFO Basics workshop focused on the INFO tool and provided feedback on the charge nurses' performances in simulated INFO debriefings. After the completion of this workshop, the ED staff are approved to conduct debriefings.

As soon as INFO was rolled out in the ED, a regular discussion was held with the INFO charge nurses, nurses, physicians, and other staff members to assess the impact of the debriefing process. Addressing participant recommendations for improvement was important to promote investment in future INFO debriefings and in addressing patient care and potential safety issues.

Now operating as a voluntary process initiated by on-duty staff, 254 inter-professional ED INFO clinical debriefing sessions have taken place from March 2016 to September 2017. Sessions have a median duration of 10 minutes and have involved over 1,300 staff. Recommendations arising from the INFO sessions have been implemented into clinical practice (Table 1).

\section{DISCUSSION}

The INFO clinical debriefing process described here is novel and adds to current literature on clinical debriefing in two important ways. Firstly, INFO addresses one of the most common barriers to regular debriefing - a lack of skilled facilitators ${ }^{6}$ - and it has proven to be a simple and effective way of building debriefing capacity in our departments. Further, it reduces the focus on physician-led debriefing and shifts leadership accountability to other team members, providing leadership opportunity for non-physicians and validating the concept of a team approach to patient care and quality improvement. Any member of the team can request an INFO debriefing, but designating responsibility to the identifiable charge nurse group has led to regular clinical debriefings in Calgary EDs. Using a structured debriefing process promotes the culture of teamwork and feedback that has resulted in various recommendations for change to clinical practice across Calgary area adult EDs. 


\section{INFO \\ DEBRIEFING TOOL \\ Basic Assumption:}

'We believe that everyone participating in patient care is intelligent, capable, cares about doing their best and wants to improve"

Adapted from the Center for Medical Simulation, Boston.

\section{SUGGESTED FLOW}

Thank group for taking time to gather

Allocate scribe and timekeeper

Go through INFO mnemonic i.e. the rules

Ask each participant for feedback making sure they do both plus and delta before moving on to the next person.

$\square$ Document feedback

$\square$ Record any recommendations that the group decides on

$\square$ Remind group of resources if more support is needed

$\square$ Note - INFO does not replace normal process

$\square$ Ask if there are any final questions

Thank group for taking part in INFO

\section{PLEASE REMEMBER}

- INFO does not replace the normal process surrounding critical events

- It is not the objective of an INFO session to assess or evaluate personal performance during this resuscitation

- Try to identify participants who you think would benefit from further counselling and approach them with the details for EFAP or PFSP
NB - It is not the objective of an INFO session to assess or evaluate personal performance during this resuscitation

\section{INFO}

I - Immediate - as soon as possible after the event.

N - Not for personal assessment - INFO is a safe environment.

F - Fast - 10-15 minutes maximum /

Feedback - expected that all members of the team will take part in a "plus / delta" format i.e. plus $=$ what went well $/$ delta $=$ what could be done differently.

Facilitated - by the nurse clinician in charge of the unit for the shift.

O - Opportunity - to ask questions / clarify events / identify areas to improve patient care.

\section{FOLLOW UP}

Employee and Family Assistance Program (EFAP)

1-877-273-3134 (AHS Staff)

$\square$ The Physician and Family Support Program (PFSP)

1-877-767-4637 (AMA)

\section{RLS}

\section{RECOMMENDATIONS FROM GROUP}

Figure 1. INFO clinical debriefing tool. 


\section{INFO \\ DEBRIEFING TOOL}

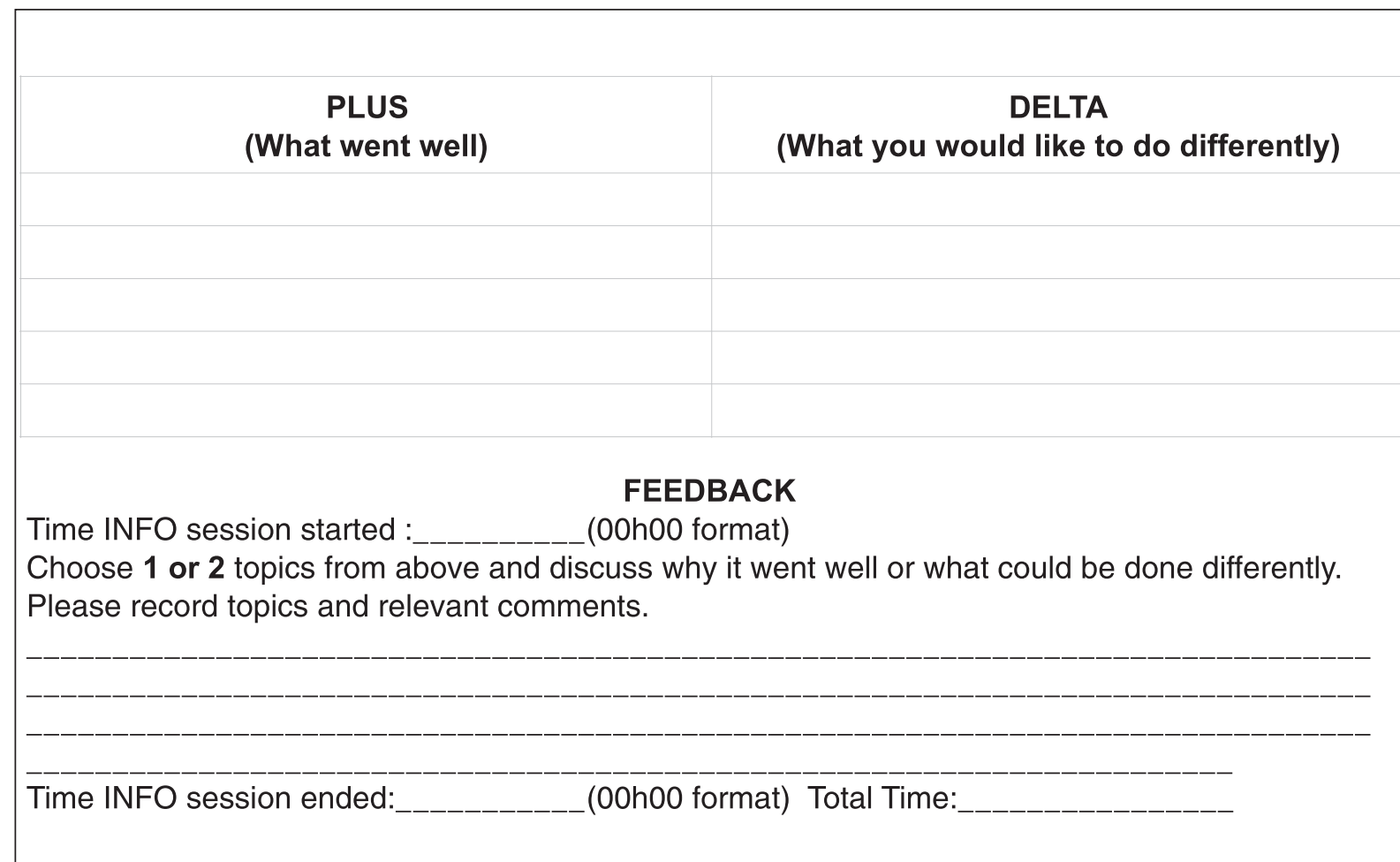

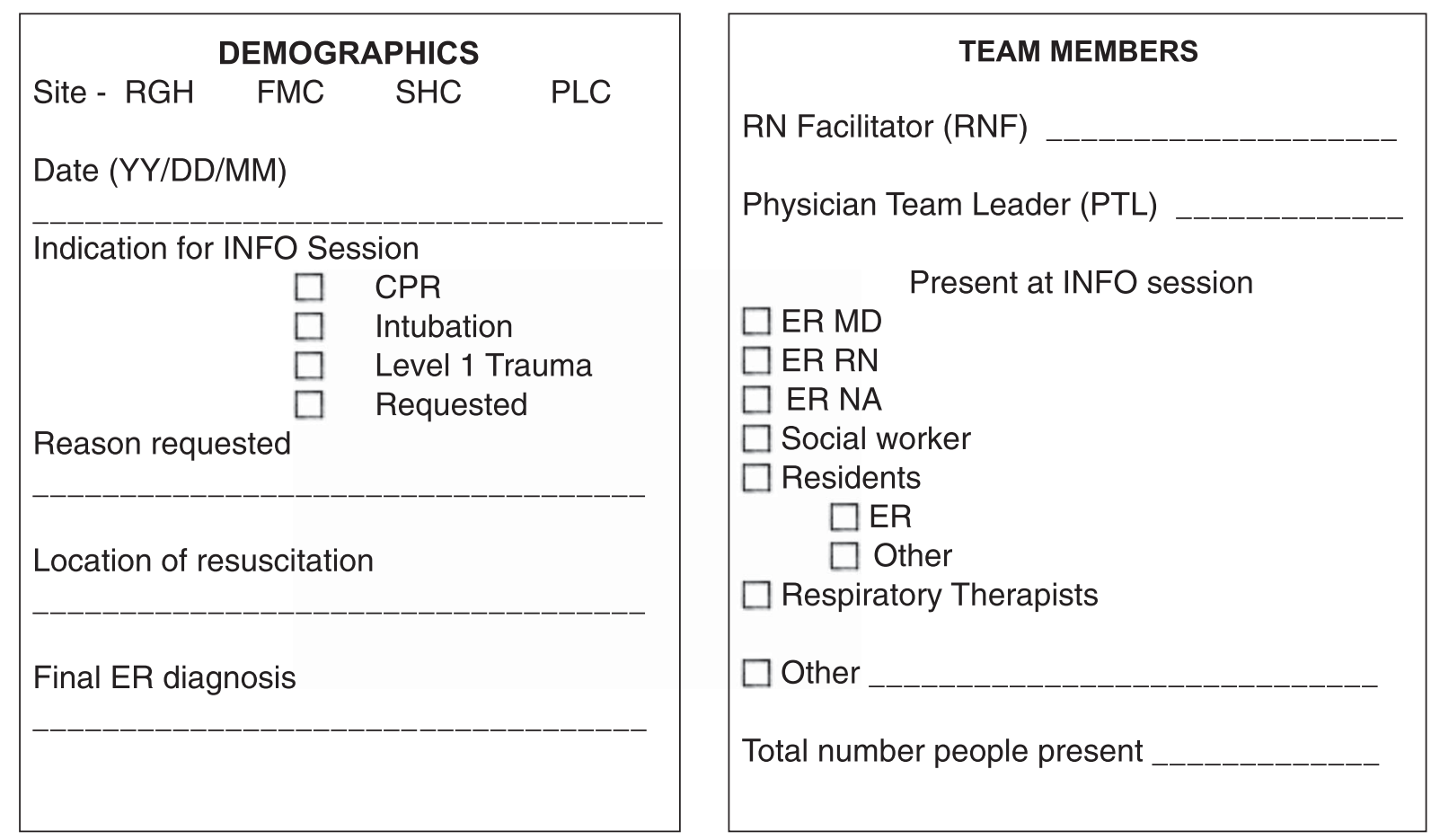

Dr. Stuart Rose

Figure 1. Continued. 


\begin{tabular}{|c|c|c|}
\hline Recommendation & Practice change & Outcome \\
\hline Improve prehospital clinical communication. & $\begin{array}{l}\text { New checklist for triage, including the } \\
\text { recommendations. }\end{array}$ & $\begin{array}{l}\text { ED teams better assembled and prepared } \\
\text { when patient arrives in the ED. }\end{array}$ \\
\hline $\begin{array}{l}\text { Address difficulty recognizing team members } \\
\text { when PPE is donned. }\end{array}$ & $\begin{array}{l}\text { Labels/name tags are distributed when } \\
\text { team is wearing PPE. }\end{array}$ & $\begin{array}{l}\text { Better team awareness and } \\
\text { communication. }\end{array}$ \\
\hline $\begin{array}{l}\text { Pre-brief with role allocation before patient gets } \\
\text { to the code room is useful. }\end{array}$ & $\begin{array}{l}\text { New pre-brief suggestion form developed } \\
\text { for resuscitation team use. }\end{array}$ & $\begin{array}{l}\text { Team is better organized once patient } \\
\text { arrives. }\end{array}$ \\
\hline $\begin{array}{l}\text { Physician summary statements are useful during } \\
\text { an HSCE. }\end{array}$ & $\begin{array}{l}\text { Physician group approached at MD } \\
\text { meeting and supportive of workshop } \\
\text { to improve communication in HSCE. }\end{array}$ & $\begin{array}{l}\text { Improved communication skills during } \\
\text { HSCE. }\end{array}$ \\
\hline $\begin{array}{l}\text { "CPR in Progress" handover from EMS to ED } \\
\text { staff in the resuscitation bay choreographed. }\end{array}$ & $\begin{array}{l}\text { CPR handover process defined and } \\
\text { standardized. }\end{array}$ & $\begin{array}{l}\text { Uninterrupted CPR for patients received in } \\
\text { the ED. }\end{array}$ \\
\hline $\begin{array}{l}\text { More opportunity to practice management of } \\
\text { uncommon clinical presentations, for example, } \\
\text { pericardiocentesis for pericardial tamponade. }\end{array}$ & $\begin{array}{l}\text { Simulation cases specifically targeted at } \\
\text { uncommon cases. }\end{array}$ & $\begin{array}{l}\text { Improved familiarity with equipment and } \\
\text { skills necessary for tasks. }\end{array}$ \\
\hline
\end{tabular}

\section{SUMMARY}

The INFO clinical debriefing process addresses two significant barriers to regular ED clinical debriefing: a lack of trained facilitators and the focus on physician-led debriefing. Our experience shows that a chargenurse-facilitated debriefing is feasible, can be successfully implemented in diverse EDs, and can be performed by relatively inexperienced debriefers. A structured approach has resulted in regular debriefings, which have become a routine part of improving team management of high stakes or unexpected clinical events in Calgary EDs.

Acknowledgements: We thank Dr. Grant Innes and Dr. Andrew McRae for their contributions in editing and revising this paper. We also thank the many people who have made suggestions and given feedback on the INFO process. In particular, we acknowledge the contributions of Dr. Aaron Johnston and Dr. Vince Grant in improving the INFO process.

Competing interests: None declared.

\section{REFERENCES}

1. Bhanji F, Donoghue AJ, Wolff MS, et al. Part 14: education: 2015 American Heart Association guidelines update for cardiopulmonary resuscitation and emergency cardiovascular care. Circulation 2015;132(18 Suppl 2):S561-73.
2. Kessler DO, Cheng A, Mullan PC. Debriefing in the emergency department after clinical events: a practical guide. Ann Emerg Med 2015;65(6):690-8.

3. Sawyer T, Loren D, Halamek LP. Post-event debriefings during neonatal care: why are we not doing them, and how can we start? 7 Perinatol 2016;36(6):415-9.

4. Wolfe H, Zebuhr C, Topjian AA, et al. Interdisciplinary ICU cardiac arrest debriefing improves survival outcomes*. Crit Care Med 2014;42(7):1688-95.

5. Theophilos T, Magyar J, Babl FE. Paediatric Research in Emergency Departments International C. Debriefing critical incidents in the paediatric emergency department: current practice and perceived needs in Australia and New Zealand. Emerg Med Australas 2009;21(6):479-83.

6. Sandhu N, Eppich W, Mikrogianakis A, et al. Postresuscitation debriefing in the pediatric emergency department: a national needs assessment. CFEM 2015;16(05): 383-92.

7. Ireland S, Gilchrist J, Maconochie I. Debriefing after failed paediatric resuscitation: a survey of current UK practice. Emerg Med 7 2008;25(6):328-30.

8. Mullan PC, Wuestner E, Kerr TD, et al. Implementation of an in situ qualitative debriefing tool for resuscitations. Resuscitation 2013;84(7):946-51.

9. Tannenbaum SI, Cerasoli CP. Do team and individual debriefs enhance performance? A meta-analysis. Hum Factors 2012;55(1):231-45.

10. Association AH. Hot debriefing form examples - Get With The Guidelines® - resuscitation clinical tools. Available at: http://www.heart.org/idc/groups/heartpublic/@wcm/@hcm/@gwtg/documents/downloadable/ucm _ 486571.pdf. 